\title{
Distribution lines insulated automatic wrapping device
}

\author{
Peng $\mathrm{Wu}^{1, \mathrm{a}}$, WenJian Zhang ${ }^{2, \mathrm{~b}}, \mathrm{Xi} \mathrm{Kou}^{3, \mathrm{c}}$ and $\mathrm{Nan} \mathrm{Li}^{4, \mathrm{~d}}$ \\ ${ }^{1}$ Baoding, Hebei Province North China Electric Power University, China \\ ${ }^{2}$ Baoding, Hebei Province North China Electric Power University, China \\ ${ }^{3}$ Baoding, Hebei Province North China Electric Power University, China \\ ${ }^{4}$ Baoding, Hebei Province North China Electric Power University, China

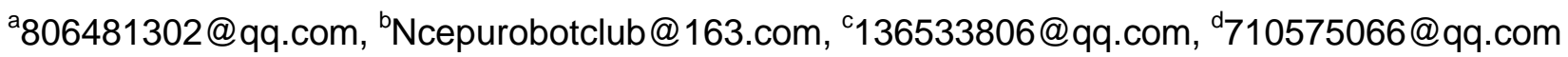

Keywords: Automatic parcel; Insulated rubber; Intelligent Remote Control

Abstract. The device is made up of walking institution, lifting institution, package institution. Walking institution mainly by package rubber pulley composition, through motor provides power led pulley scroll, to achieve robot in overhead line of walking function; lifting institution is made by two big cantilevers constitute of scissors structure, cantilevers end with motor, driving is imported screw nut, by wireless remote control unit controls motor rotated, screw nut rotates to control two cantilevers of angle change to achieve device of landing; package institution is made up of conveying device and clamp institution, conveying device dues to mechanical hand to guide zip around pull, clamp institution, as well as eight clamping gripper powered by the motors, and the angle changes. Ethylene-propensity rubber is selected as insulation material, the material has good aging resistance, abrasion resistance, excellent electrical insulation properties, is good insulating material for wire,cable,high pressure and ultra high pressure, and the insulated coat for opening snap-joint structure, simple operation,easy to use. Appliance parts work together as a whole together with $10 \mathrm{kV}$ insulation repair work on the low-voltage distribution line.

\section{Introduction}

It is common that the variable barriers like the trees on the $10 \mathrm{kv}$ distribution lines of rural overhead line,in order to guarantee distribution lines safe and reliable,we frequently take measures to package electro-insulating rubber by enhancing the insulativity of $10 \mathrm{kv}$ distribution lines,ensuring the power distribution safely and orderly.

Presently,distribution lines insulated wrapping generally is done by electric lift truck to send engineer to constructions,but such behaviors isn't appropriate for the littoral and high-speed-developing,inner cities where the terrain is smooth and open,with huge limitations.But there also exists such complicated environment in constructions, such as low-speed-developing countries, the rough terrain and so on.Not only the vehicles are hard reach the constructions, but they also own the questions like low labor intensity,low working performance, unstable working quality, particularly the serious hidden dangers of personal security, the human-induced restoration is more and more increasingly not adjust to the the need of modern electrified network as well as rapid expansion of economic society.What's more,the territory of distribution lines insulated automatic wrapping,so far,there is no research achievements or patents.As a result,it is especially necessary for us to exploit a distribution lines insulated automatic wrapping device to take place of the human-induced restoration. 
The text adopts technical proposal as: the device is made up of walking, lifting institution, package institution.Walking institution make robot in overhead line of walking function,lifting institution achieve device of landing,package institution finish package and transportation of electro-insulating rubber.

The device is powered by lithium battery, which is controlled by wireless command to execute the action of electrical machines,lifting institution is made by two big cantilevers constitute of scissors structure,the cantilevers end with motor, driving is imported screw nut, by wireless remote control unit controls motor rotated, screw nut rotates to control two cantilevers of angle change to achieve device of landing. Walking institution depends on motor provides power led pulley scroll,meanwhile we use technology of encapsulation to enhance the friction between pulley and lines.Package institution is made up of conveying device and clamp institution, conveying device dues to mechanical hand to guide zip around pull, clamp institution, as well as eight clamping gripper powered by the motors,and the angle changes.By coordination among bracket mechanical hand and clamping gripper,finally the electro-insulating rubber is packaged on the surface of the lines.Ethylene-propensity rubber is selected as insulation material, the material has good aging resistance, abrasion resistance, excellent electrical insulation properties, is good insulating material for wire,cable,high pressure and ultra high pressure, and the insulated coat for opening snap-joint structure, simple operation, easy to use.

\section{Entire introduction}

\section{Entire structure and insulated coat introduction}

From the picture one of the device is made up of walking institution,lifting institution,package institution.Walking institution mainly by package rubber pulley composition, through motor provides power led pulley scroll, to achieve robot in overhead line of walking function.Lifting institution uses screw nut and scissors structure,scissors is connected by two big cantilevers,structure screw nut rotates to control angle changed to achieve device of landing.Package institution is the core of whole device,by coordination among bracket tray mechanical hand and clamping gripper,finally the electro-insulating rubber is packaged on the surface of the lines.

Ethylene-propensity rubber is selected as insulation material, the material has good aging resistance, abrasion resistance, excellent electrical insulation properties, is good insulating material for wire,cable, high pressure and ultra high pressure, and the insulated coat for opening snap-joint structure, simple operation, easy to use. 


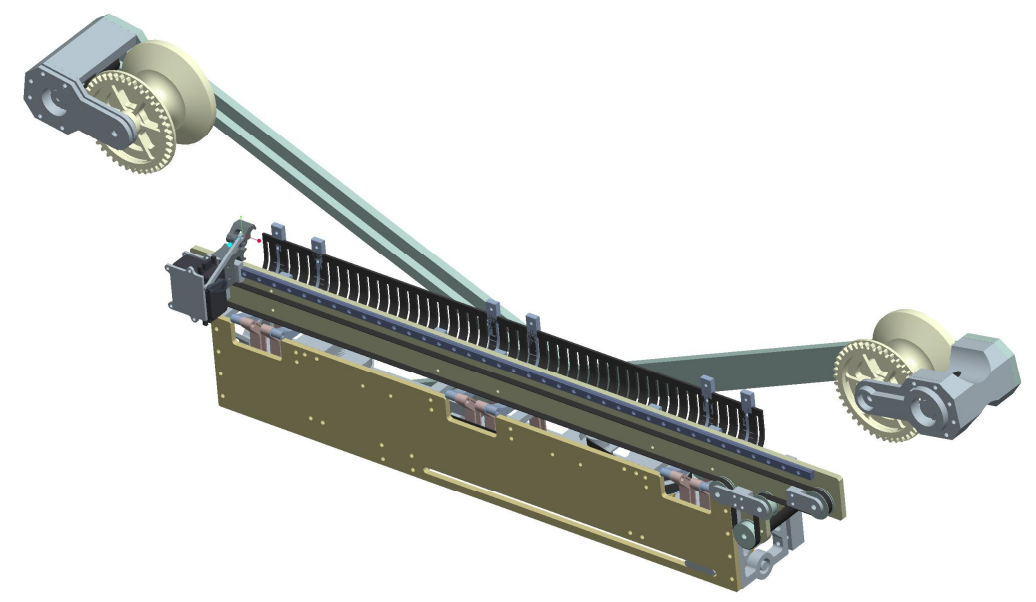

Picture 1 The entire structure

\section{The device structure introduction}

The device is made up of walking institution, lifting institution, package institution.Lifting institution is made by two big cantilevers constitute of scissors structure, the cantilevers end with motors, screw nut is imported to the transmission, by wireless remote control unit controls motor rotated, screw nut rotates to control two cantilevers of angle changed to achieve device of landing.Screw nut provide device the stable speed of landing,and its high precision pledge the lifting institution stable and reliable.

Walking institution depends on motor provides power led pulley scroll,walking on the lines by friction between pulley and lines.Meanwhile we use technology of encapsulation to enhance the friction between pulley and lines.The motors is separating from battery, if the slider haven't arrived the working location, the limited switch turns on, the power supply is done by limited switch.

Package institution is made up of conveying device and clamp institution, conveying device dues to mechanical hand to guide zip around pull,mechanical hand led the zip to the right end,in order to prove snap-joint straining.Clamp institution,is made of bracket,as well as eight clamping gripper powered by the motors, and the angle changes, thus finally achieve clamp the electro-insulating rubber.Package institution is sent to the aim by lifting institution,the bracket controls mechanical paw expand or close depends on connecting rod.The open end of lines' repaired chips fit,the mechanical hand led the zip to the right end,to strain insulated repaired chips. The package paw grasp gradually,in order to make open end of repaired chips completely fit,mechanical hand led the zip to the left end,and lock lines.There are heater band on the package clamp,after lines are entirely packaged and locked,heater band start heating,the repaired chips are heated and shrink as well as tightly packaged on the lines, the device finish working.

\section{Wireless communication remote control system}

Wireless communication remote control system is a kind of man-machine interface that it is used to appear such information as examining motors working condition,measuring the distance between the device and insulation,packaging process,giving an alarm and so on.Various working parameters of device are transmitted to the client APP by means of wireless network. The device is powered by the remote control as well as client APP. 


\section{Working process instruction}

Let two big cantilevers of angle to the smallest,it is hanging condition, we use insulated rod to put the device on the faulted lines.After the device stably hang on the lines, the motors at the end of cantilevers controls them of a bigger angle,now the device is walking condition. When device reaches the damaged parts, the device stop walking, and the angle is at a maximum, the cable are surrounds with lines' repaired chips.Package institution is sent to the aim by lifting institution,the bracket controls mechanical paw expand or close depends on connecting rod.The open end of lines' repaired chips fit,the mechanical hand led the zip to the right end,to strain insulated repaired chips. The package paw grasp gradually,in order to make open end of repaired chips completely fit,mechanical hand led the zip to the left end,and lock lines. There are heater band on the package clamp,after lines are entirely packaged and locked,heater band start heating, the repaired chips are heated and shrink as well as tightly packaged on the lines,the device finish working. The mechanical hand and clamps loosen,two big cantilevers turn to walking condition, the device finish working and go away.

\section{Conclusion}

During $10 \mathrm{kv}$ distribution lines, the question about damages of insulation is much more serious,repairing insulation is extraordinarily necessary and significant.But the present method to repair insulation is not only not apply to the complicated working condition,but the artificial repairing is also existing huge potential dangers as well as a high charge.But such behaviors isn't appropriate for the littoral and high-speed-developing,inner cities where the terrain is smooth and open. Distribution lines insulated automatic wrapping device can finish the package process of $10 \mathrm{kv}$ distribution lines in any extremely environments. The successful develop of the device,not just improve the reliability of repairing,advance the assurance factor of electrical repairing,even decrease the cost of a whole repairing process. At the background of sustainable development, the device has a bright prospect.

\section{References}

[1] Zhang Chenbo.On the transmission and distribution lines in operation and management problems and improvements[J].Guangdong Science and Technology.2009.(22):19-20.

[2] Yu Xi.Safe operation and maintenance of transmission and distribution lines Technical Analysis[J].Super science.2014.(30):71-72.

[3] Sun Yingwen.Small variable radius pipeline repair robot design big technology[J].Fortune World.2011.(14):77-77.

[4] Zhao Yingfeng.XLPE power cable insulation condition assessment and self-healing remediation technology[D].Southwest Jiaotong University.2013.

[5] Wang Runfang,Wang Yuechao,Zhao Yiwen and other.Development of a multi-agency complex intelligent mobile robots[J].Robot.2004.26(4):289-294. 